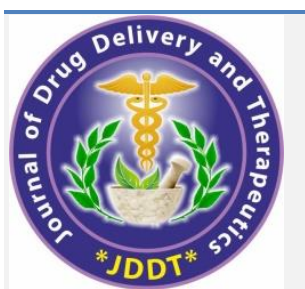

Open Access Full Text Article

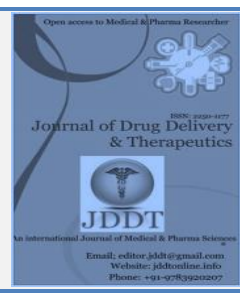

Research Article

\title{
Formulation, Development and Evaluation of Gastroretentive Sustained Release Tablets of Lansoprazole Using Natural Polymer
}

\author{
Sonam, Nilesh Jain*, Jitendra Banveer \\ Sagar Institute of Research Technology \& Science - Pharmacy, Bhopal (M.P.), India
}

Article Info:

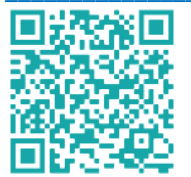

\section{Article History:}

Received 06 September 2021 Reviewed 28 October 2021

Accepted 07 November 2021

Published 15 November 2021

Cite this article as:

Sonam, Jain N, Banveer J, Formulation, Development and Evaluation of Gastroretentive Sustained Release Tablets of Lansoprazole Using Natural Polymer, Journal of Drug Delivery and Therapeutics. 2021; 11(5-S):108-112

DOI: http://dx.doi.org/10.22270/jddt.v11i5-S.5087

\section{*Address for Correspondence:}

Dr. (Prof.) Nilesh Jain, Sagar Institute of Research Technology \& Science - Pharmacy, Bhopal (M.P.), India

\section{Abstract}

The goal of this study is to develop a long-acting Lansoprazole delivery system. Lansoprazole belongs to a class of antisecretory drugs known as substituted benzimidazoles, which decrease gastric acid secretion by inhibiting the $(\mathrm{H}+\mathrm{K}+\mathrm{+}$-ATPase enzyme system at the secretory membrane of the stomach parietal cell. Due to its mechanism of action, despite its short half-life of 1-5 hours, it can effectively block acid secretion for 24 hours. However, as his plasma concentration falls, the effect will diminish. Lansoprazole will be given as a sustained release tablet to avoid multiple dosing or to reduce the frequency of dose. Lansoprazole was produced and analysed utilizing natural and synthetic polymers such as Xanthan gum, Gellan gum, Carbopol 940 P, and Chitosan. Based on the findings of this experiment, it was determined that formulation F7 demonstrated sustained drug release for up to 12 hours in all developed formulations. Formulation (F1, F2, F3, F4, F5, and F6) were tested in vitro for drug release. For the improved formulation $\mathrm{F}$, the formulation and release kinetics were estimated. When the regression coefficient values of were evaluated, it was found that Peppas had the highest ' $r 2$ ' value, 0.952 , indicating that drug release from formulations followed Peppas release kinetics.

Key words: Lansoprazole, Sustain release tablets, Synthetic and Natural Polymers, formulation, evaluation

\section{INTRODUCTION}

The current peroral sustained release medication delivery methods have a maximum therapeutic efficacy of 24 hours. These systems are designed primarily for medicines with a short elimination half-life. Drugs with a lengthy half-life, on the other hand, qualify if a reduction in steady-state fluctuation is required ${ }^{1}$.

The main goal of therapy for many medications is to achieve a therapeutically effective and non-toxic steady-state blood or tissue level for a sustained length of time. Various types of drug delivery systems are available to achieve improved therapeutic activity, with sustained release systems getting a lot of traction due to their numerous advantages over others like ease of administration, convenience and noninvasiveness.

The most common route of drug delivery is through the mouth. Despite the fact that multiple routes of administration are employed to deliver medications, the oral route remains the most popular. Even for continuous release systems, the oral route has received the greatest attention due to the versatility in dosage form design that the oral route provides ${ }^{2}$.

A drug delivery system (DDS) is a formulation or a technology that allows a medicinal material to be introduced into the body and increases its efficacy and safety by managing the rate, time, and location of drug release. The administration of the therapeutic product, the release of the active chemicals by the product, and the subsequent transport of the active ingredients across biological membranes to the site of action are all parts of this process. The phrase "therapeutic substance" also refers to an agent, such as gene therapy, that induces the active therapeutic agent's synthesis in vivo. A drug delivery system serves as a link between the patient and the medication. This distinction between drug and device is critical since it is the criterion used by the drug or medicine control agency to regulate the delivery method. A device is rigorously regulated as a device if it is put into the human body for objectives other than drug administration, such as therapeutic impact by a physical modality or a drug may be included into the device to prevent complications resulting from the device. The distinction between pharmaceuticals and devices is broad, and whether a product belongs in one or the other is determined on a case-by-case basis. In the world of pharmaceutical technology, sustained release (SR) has provided a fresh breakthrough for revolutionary drug delivery systems. Sustained release refers to any dose type that delivers drug over a long period of time or indicates that the system can provide some level of therapeutic control, whether temporally, spatially, or both. Sustained release systems rarely achieve zero order release and instead 
attempt to imitate it by delivering the medication in a sluggish first order. Multiple doses of medicine are held within a dosage form and each dose is released at a periodic interval in a repeat action tablet, which is an alternate type of sustained release in which multiple doses are contained within a dosage form and each dose is delivered at a periodic interval.

Sustained release (SR) preparations are not new, however there are a few changes that have been made. When compared to "rapid" or "standard" release preparations, they are also referred to as "long acting" or "delayed release." The term is occasionally confused with "controlled release," which refers to more sophisticated release control that isn't limited to the time dimension ${ }^{3}$. Polysaccharides and proteins are the focus of the majority of natural polymer research in drug delivery systems. In the various drug delivery systems, a variety of natural, synthetic, and semi-synthetic polymer materials are used. Natural, synthetic, and semi-synthetic polymers are all employed, but natural mucilage is favoured over synthetic and semi-synthetic polymers since it is less expensive, more widely available, nontoxic, and less irritating in nature.

Lansoprazole is an acid suppressant that is licenced for the short-term treatment of active gastric ulcers, active duodenal ulcers, erosive reflux ulcers, esophagitis, and NSAIDSinduced gastric ulcers. Lansoprazole is an acid that metabolises into two inactive and metabolites. Its oral bioavailability is claimed to be $80-90$ percent, with a peak plasma concentration of 1-5 hours. The apparent volume of distribution is quite small $(0.4 \mathrm{~L} / \mathrm{Kg})$ and 97 percent of Lansoprazole is associated with plasma protein. Due to its mechanism of action, despite its short half life of 1-5 hours, it can effectively block acid secretion for 24 hours. However, as his plasma concentration falls, the effect will diminish.

Lansoprazole will be given as a sustained release tablet to avoid multiple dosing or to reduce the frequency of dose. The majority of research has been done to develop a formulation, i.e. a Lansoprazole sustained-release tablet, using synthetic polymer.

\section{MATERIAL AND METHODS}

\section{Material}

Lansoprazole was received as gift sample from pharmaceutical company. Hydroxypropyl methylcellulose (HPMC K4M) was procured from Meditab Specialities Pvt. Ltd., Satara. Xanthan gum, Gellan gum, Chitosan was purchased from S.D fine chemicals, Mumbai. Sodium bicarbonate, citric acid, magnesium stearate, talc were purchased from Mapromax, Life sciences Pvt. Ltd., Dehradun. Other solvents and chemicals used in the research were of LR grade. All the studies were carried in distilled water.

\section{Methods}

\section{Method for preparation of Lansoprazole floating gastroretentive (FGR) tablets}

Direct compression was used to make the gas-generating floating Lansoprazole tablets ${ }^{4}$. Direct compression was used to create nine alternative formulations (F1, F2, F3, F4, F5, F6, F7, F8, and F9). All of the polymers, drugs, and excipients were filtered through strainer no. 40 . The total weight and proportion of drug and polymers were calculated using the table no. 1 , and all of the definitions were used to aid in the evaluation of the parameters.

\section{Optimization of Gastro retentive floating tablets of Lansoprazole}

Optimization of formulation carried out on the basis of OVAT (One variable at time) using amount of excipient used like Excipients like Xanthan gum, Gellan gum, Chitosan and Carbopol 940 P.

Table 1: Various formulations of Lansoprazole Gastroretentive tablets

\begin{tabular}{|l|l|l|l|l|l|l|l|l|l|}
\hline Excipients (mg) & F1 & F2 & F3 & F4 & F5 & F6 & F7 & F8 & F9 \\
\hline Lansoprazole & 30 & 30 & 30 & 30 & 30 & 30 & 30 & 30 & 30 \\
\hline Xanthan gum & 100 & 120 & 140 & - & - & - & 50 & 60 & 70 \\
\hline Gellan gum & - & - & - & 100 & 120 & 140 & 50 & 60 & 70 \\
\hline Carbopol 940 P & - & - & - & - & - & - & 20 & 20 & 20 \\
\hline Chitosan & 30 & 30 & 30 & 30 & 30 & 30 & 30 & 30 & 30 \\
\hline Citric acid & 5 & 5 & 5 & 5 & 5 & 5 & 5 & 5 & 5 \\
\hline NaHCO & 20 & 20 & 20 & 20 & 20 & 20 & 20 & 20 & 20 \\
\hline Mg(C $\left.\mathbf{1}_{\mathbf{3}} \mathbf{H}_{35} \mathbf{O}_{2}\right)_{2}$ & 10 & 10 & 10 & 10 & 10 & 10 & 10 & 10 & 10 \\
\hline Talc & 5 & 5 & 5 & 5 & 5 & 5 & 5 & 5 & 5 \\
\hline Lactose & 100 & 80 & 60 & 100 & 80 & 60 & 80 & 60 & 40 \\
\hline Total Weight & 300 & 300 & 300 & 300 & 300 & 300 & 300 & 300 & 300 \\
\hline
\end{tabular}

Sodium bicarbonate, Citric acid, Magnesium Stearate, Xanthan gum, Gellan gum, Chitosan, and Carbopol 940 P, Sodium bicarbonate, Citric acid, and Magnesium Stearate were chosen for testing. As a gas generator, sodium bicarbonate and citric acid were used. The drug and several excipients were filtered through a 40 mesh sieve. Weighing the required amount of medication and polymer, transferring it to a polyethylene pack, and blending it for 15 minutes. Add magnesium stearate and talc to the concoction and blend for another 5 minutes.

Evaluation of Precompression Parameter ${ }^{5-6}$

1. Bulk density: The tapped bulk density (TBD) and the loose bulk density (LBD) were calculated. The LBD and 
TBD were estimated using the following formulas after a precisely weighed amount of granules was placed in a 50 $\mathrm{ml}$ capacity measuring cylinder and tapped 100 times on a level hard wooden surface.

$$
\begin{gathered}
\text { LBD (Loose Bulk Density) }=\frac{\text { Mass of powder }}{\text { Volume of Packing }} \\
\text { TBD (Tapped Bulk Density) }=\frac{\text { Mass of powder }}{\text { Tapped Volume of Packing }}
\end{gathered}
$$

2. Carr's Compressibility index: Carr's compressibility index was used to determine the percent compressibility of the powder mix, which was obtained using the formula below:-

$$
\text { Carr's Index }=\frac{\text { TBD }- \text { LBD }}{\text { TBD }} \text { X } 100
$$

3. Hausner's ratio: It is determined by comparing tapped density to the bulk density by using following equation:-

$$
\text { Housner's ratio }=\frac{\text { Tapped bulk density }}{\text { Loose Bulk density }}
$$

Hausner's ratio value $<1.25$ shows better flow properties

\section{Evaluation of tablets}

All the tablets were evaluated for following various parameters which includes;

\section{General Appearance}

Organoleptic properties such as colour, odour, and form were tested on five tablets chosen at random from distinct batches. Visual appearance was assessed. Very good $(+++)$, good $(++)$, fair $(+)$ poor $(-)$, very poor $(-)$.

\section{Thickness and diameter}

Vernier callipers were used to measure the thickness and diameter of the tablets. Five tablets from each batch were used to get an average value ${ }^{7}$.

\section{Drug content}

Twenty tablets were ingested, and the amount of drug in each tablet was calculated 8 . The tablets were crushed in a mortar, and $10 \mathrm{mg}$ of drug powder was transferred to a $10 \mathrm{ml}$ standard flask. The powder was dissolved in $5 \mathrm{~mL}$ of $0.1 \mathrm{~N}$ $\mathrm{HCl}$ and then made up to volume with the same solution. The sample was well mixed before passing through a 0.45 membrane filter. The filtered solution was diluted appropriately and drug concentration was determined using a UV spectrophotometer set to $296 \mathrm{~nm}$ with $0.1 \mathrm{~N} \mathrm{HCl}$ as a blank.

\section{Hardness}

For each formulation, the hardness of five tablets was resolved utilizing the Monsanto hardness tester ${ }^{7}$.

\section{Friability}

The friability of a sample of 10 tablets was estimated utilizing a Friability tester (Electro Lab). Ten tablets were weighed, rotated at $25 \mathrm{rpm}$ for 4 minutes. Tablets were reweighed after removal of fines (dedusted) and the percentage of weight loss was calculated ${ }^{8}$.

\section{Uniformity of weight}

Twenty tablets were randomly selected from each batch individually weighed, the average weight and standard deviation of 20 tablets was calculated.

\section{In vitro buoyancy studies:}

The floating lag time approach described by Rosa et al. was used to determine in vitro buoyancy. Separately, the pills were placed in a $100 \mathrm{~mL}$ glass beaker containing simulated stomach juice with a $\mathrm{pH}$ of 1.2 , as recommended by the USP. Floating lag time was calculated as the time required for the tablet to increase to the outside and float ${ }^{9}$.

\section{Dissolution rate studies}

The sample was given an in vitro drug release utilising a USP-type II dissolving equipment (Paddle type). The dissolution medium, $900 \mathrm{ml} 0.1 \mathrm{~N} \mathrm{HCl}$, was added to the dissolution flask at a temperature of $370.5 \mathrm{oC}$ and a rotational speed of 75. In each container of the dissolution device, one prepared Lansoprazole pill was placed. The mechanical assembly was allowed to run for a total of 10 hours. Using a $10 \mathrm{ml}$ pipette, a $5 \mathrm{ml}$ sample was pulled back every 1 hour for a total of 10 hours. The new disintegration medium (37oC) was replaced with an equal amount of the sample each time, and UV/Visible spectroscopy was used to measure the absorbance at $296 \mathrm{~nm}$.

\section{RESULTS AND DISCUSSION}

Before compressing powders into tablets, the loose bulk density (LBD) and tapered bulk density (TBD) of powders of various formulations were assessed. For all formulations, the bulk density and tapped density ranged from 0.365 to $0.378 \mathrm{gm} / \mathrm{cm} 3$ and 0.469 to $0.489 \mathrm{gm} / \mathrm{cm} 3$, respectively Table 2.

The obtained results are within acceptable limits. There is a very small difference between bulk density and tapped density. The percent compressibility of the powder can be calculated using this result.

The Hausner's ratio for all formulations varies between 1.285 and 1.327. The results of Hausner's ratio for all formulations were displayed, indicating that all formulations have the same flow ability Table 2 .

All of the formulations' compressibility indexes vary from 22.199 percent to 24.632 percent. The results showed that all of the formulations had high flow ability, and the powder had good compressibility Table 2 .

The thickness of the tablets was reported in the micrometer $(\mathrm{mm})$.The thickness of tablet indicates that, die fill was uniform. The thickness depends on the size of the punches (8 $\mathrm{mm}$ ) and the weight of one tablet $(300 \mathrm{mg})$. The value of thickness ranges between $3.12 \pm 0.33$ to $3.25 \pm 0.21 \mathrm{~mm}$ Table 3.

Friability determines the strength of the tablets. The friability for all the formulations was below 1\% indicating that the friability was within the prescribed limits. The results of friability test indicate that the tablet possesses good mechanical strength. The friability value ranges from $0.658 \pm 0.014$ to $0.785 \pm 0.041$ Table 3 .

The mean hardness values for all of the formulations were determined using a Monsanto hardness tester. The hardness value varies between 6.20 .4 and $6.50 .2 \mathrm{~kg} / \mathrm{cm}^{2}$ Table 3 .

Twenty tablets from each formulation were chosen at random and examined. The information gathered was nearly uniform. The average weight of the tablets ranges from 299 to $306 \mathrm{mg}$. All of the tablets passed the weight variation test since the percent weight variation was less than $5 \%$ of the total weight, as defined by the USP Pharmacopoeia Table 3 .

The percent drug content of all formed tablets was confirmed to be within the acceptable range. The percent drug content 
value of Lansoprazole ranged from $98.120 .45 \%$ to $99.450 .32 \%$. The findings within the range imply that the mixing is uniform Table 7.3.

Formulation (F1, F2, F3, F4, F5, and F6) were tested in vitro for drug release. For the improved formulation F7, the formulation and release kinetics were estimated. When the regression coefficient values of were examined, it was discovered that Peppas had the highest ' $r 2$ ' value, 0.952 , indicating that drug release from formulations followed Peppas release kinetics. table 4, 5 and 6.

Table 2: Result of pre-compression properties of Lansoprazole FGR (floating gastroretentive) tablets

\begin{tabular}{|c|c|c|c|c|}
\hline Formulation Code & Bulk density(gm/ml) & $\begin{array}{c}\text { Tapped } \\
\text { density(gm/ml) }\end{array}$ & Compressibility index & Hausner ratio \\
\hline F1 & 0.358 & 0.475 & 24.632 & 1.327 \\
\hline F2 & 0.356 & 0.469 & 24.094 & 1.317 \\
\hline F3 & 0.374 & 0.482 & 22.407 & 1.289 \\
\hline F4 & 0.369 & 0.476 & 22.479 & 1.290 \\
\hline F5 & 0.373 & 0.482 & 22.614 & 1.285 \\
\hline F6 & 0.368 & 0.473 & 23.158 & 1.301 \\
\hline F7 & 0.365 & 0.475 & 23.203 & 1.302 \\
\hline F8 & 0.374 & 0.487 & 22.699 & 1.294 \\
\hline
\end{tabular}

Table 3: Results of post compression properties of Lansoprazole FGR tablets

\begin{tabular}{|c|c|c|c|c|c|c|c|}
\hline $\begin{array}{c}\text { Formulation } \\
\text { code }\end{array}$ & $\begin{array}{c}\text { Thickness } \\
\mathbf{( m m )}\end{array}$ & $\begin{array}{c}\text { Hardness } \\
\mathbf{( k g / \mathbf { c m } )} \\
\mathbf{n = 3}\end{array}$ & $\begin{array}{c}\text { Weight } \\
\text { variation } \\
\mathbf{( m g )} \\
\mathbf{n = 3}\end{array}$ & $\begin{array}{c}\text { Friability } \\
\mathbf{( \% )} \\
\mathbf{n = 3}\end{array}$ & $\begin{array}{c}\text { Drug content } \\
\mathbf{( \% )} \\
\mathbf{n = 3}\end{array}$ & $\begin{array}{c}\text { Total } \\
\mathbf{f l o a t i n g} \\
\text { duration (h) }\end{array}$ & $\begin{array}{c}\text { Floating lag } \\
\text { times (sec) }\end{array}$ \\
\hline F1 & $3.12 \pm 0.32$ & $6.2 \pm 0.2$ & $305 \pm 5$ & $0.708 \pm 0.012$ & $98.12 \pm 0.45$ & $>12$ & 57 \\
\hline F2 & $3.15 \pm 0.25$ & $6.3 \pm 0.1$ & $300 \pm 4$ & $0.714 \pm 0.032$ & $98.85 \pm 0.23$ & $>12$ & 52 \\
\hline F3 & $3.25 \pm 0.21$ & $6.5 \pm 0.2$ & $302 \pm 3$ & $0.658 \pm 0.014$ & $98.78 \pm 0.25$ & $>12$ & 48 \\
\hline F4 & $3.14 \pm 0.12$ & $6.3 \pm 0.2$ & $299 \pm 2$ & $0.745 \pm 0.022$ & $98.65 \pm 0.45$ & $>12$ & 52 \\
\hline F5 & $3.16 \pm 0.22$ & $6.4 \pm 0.3$ & $303 \pm 4$ & $0.775 \pm 0.026$ & $98.84 \pm 0.32$ & $>12$ & 49 \\
\hline F6 & $3.14 \pm 0.36$ & $6.5 \pm 0.3$ & $305 \pm 5$ & $0.659 \pm 0.033$ & $99.05 \pm 0.14$ & $>12$ & 45 \\
\hline F7 & $3.13 \pm 0.25$ & $6.2 \pm 0.4$ & $306 \pm 6$ & $0.785 \pm 0.041$ & $98.85 \pm 0.25$ & $>12$ & 36 \\
\hline F8 & $3.14 \pm 0.21$ & $6.4 \pm 0.2$ & $304 \pm 4$ & $0.712 \pm 0.036$ & $99.45 \pm 0.32$ & $>12$ & 22 \\
\hline F9 & $3.12 \pm 0.33$ & $6.5 \pm 0.3$ & $307 \pm 5$ & $0.745 \pm 0.025$ & $98.78 \pm 0.32$ & $>12$ & 39 \\
\hline
\end{tabular}

Table 4: In-vitro drug release study of FGR tablets

\begin{tabular}{|c|c|c|c|c|c|c|c|c|c|}
\hline Time & \multicolumn{9}{|c|}{ \% Cumulative Drug Release } \\
\hline (hr) & F1 & F2 & F3 & F4 & F5 & F6 & F7 & F8 & F9 \\
\hline 0.5 & 39.98 & 35.65 & 33.12 & 35.65 & 33.25 & 32.25 & 22.32 & 18.85 & 15.58 \\
\hline 1 & 53.32 & 49.98 & 43.32 & 48.85 & 46.65 & 45.58 & 36.75 & 35.45 & 32.25 \\
\hline 1.5 & 69.98 & 65.58 & 60.47 & 65.58 & 59.98 & 53.32 & 44.32 & 42.23 & 40.47 \\
\hline 2 & 88.85 & 78.85 & 73.32 & 83.32 & 82.23 & 69.98 & 56.65 & 53.32 & 49.98 \\
\hline 3 & 98.78 & 84.45 & 80.47 & 96.65 & 95.65 & 78.85 & 65.56 & 62.23 & 58.85 \\
\hline 4 & - & 99.12 & 89.98 & 98.85 & 98.85 & 89.98 & 78.89 & 70.23 & 68.87 \\
\hline 6 & - & - & 98.85 & - & 99.47 & 98.78 & 83.23 & 80.47 & 78.84 \\
\hline 8 & - & - & - & - & - & 99.12 & 89.98 & 85.56 & 83.32 \\
\hline 12 & - & - & - & - & - & - & 99.74 & 89.98 & 85.458 \\
\hline
\end{tabular}


Table 5: In-vitro drug release data for optimized formulation F7

\begin{tabular}{|c|c|c|c|c|c|c|}
\hline Time (h) & $\begin{array}{c}\text { Square Root } \\
\text { of Time(h) }\end{array}$ & Log Time & $\begin{array}{c}\text { Cumulative*\% } \\
\text { Drug Release }\end{array}$ & $\begin{array}{c}\text { Log Cumulative } \\
\text { \% Drug Release }\end{array}$ & $\begin{array}{c}\text { Cumulative \%o } \\
\text { Drug Remaining }\end{array}$ & $\begin{array}{c}\text { Log Cumulative } \\
\text { \% Drug } \\
\text { Remaining }\end{array}$ \\
\hline 0.5 & 0.707 & -0.301 & 22.32 & 1.349 & 77.68 & 1.890 \\
\hline 1 & 1 & 0 & 36.75 & 1.565 & 63.25 & 1.801 \\
\hline 1.5 & 1.225 & 0.176 & 44.32 & 1.647 & 55.68 & 1.746 \\
\hline 2 & 1.414 & 0.301 & 56.65 & 1.753 & 43.35 & 1.637 \\
\hline 3 & 1.732 & 0.477 & 65.56 & 1.817 & 34.44 & 1.537 \\
\hline 4 & 2 & 0.602 & 78.89 & 1.897 & 21.11 & 1.324 \\
\hline 6 & 2.449 & 0.778 & 83.23 & 1.920 & 16.77 & 1.225 \\
\hline 8 & 2.828 & 0.903 & 89.98 & 1.954 & 10.02 & 1.001 \\
\hline 12 & 3.464 & 1.079 & 99.74 & 1.999 & 0.26 & -0.585 \\
\hline
\end{tabular}

Table 6: Regression analysis data of Lansoprazole Floating Tablets

\begin{tabular}{|c|c|c|c|c|}
\hline \multirow{2}{*}{ Batch } & Zero Order & First Order & Higuchi & Peppas \\
\cline { 2 - 5 } & $\mathbf{R}^{\mathbf{2}}$ & $\mathbf{R}^{\mathbf{2}}$ & $\mathbf{R}^{\mathbf{2}}$ & $\mathbf{R}^{\mathbf{2}}$ \\
\hline F7 & 0.812 & 0.903 & 0.801 & 0.952 \\
\hline
\end{tabular}

\section{CONCLUSION}

Long-acting lansoprazole formulation was created and tested. Based on the findings of this experiment, it was determined that formulation F7 demonstrated sustained drug release for up to 12 hours in all developed formulations. Formulation (F1, F2, F3, F4, F5, and F6) were tested in vitro for drug release. For the improved formulation F7, the formulation and release kinetics were estimated. When the regression coefficient values of were examined, it was discovered that Peppas had the highest ' $r 2$ ' value, 0.952 , indicating that drug release from formulations followed Peppas release kinetics.

\section{REFERENCES}

1. Howard C. Ansel, NIcholos G. Popvich, lyold V. Allen, pharmaceutical dosage forms and Drug Delivery system. 1st ed.; 1995.p.78.4.

2. Jain N.K and Sharma S.N. A text book of professional pharmacy. 1st ed.; 1995.p.78.5.

3. Samuel Harder and Glenn V. Buskirk. Pilot Plant Scale-Up Techniques. In The Theory and Practice of Industrial Pharmacy.3rd ed., 1991, p. 687-702.

4. Wasnik S, Parmar P, Singh D, Ram A. Preparation and characterization of floating drug delivery system of azithromycin. Acta Pol Pharm 2012; 69:515-22.
5. Kadivar A, Kamalidehghan B, Javar HA, Davoudi ET, Zaharuddin ND, Sabeti B, et al. Formulation and in vitro, in vivo evaluation of effervescent floating sustained release imatinib mesylate tablet. PLOS One 2015; 10:1-23. https://doi.org/10.1371/journal.pone.0126874

6. Rahim SA, Carter PA, Elkordy AA. Design and evaluation of effervescent floating tablets based on hydroxyethyl cellulose and sodium alginate using pentoxifylline as a model drug. Drug Des Dev Ther 2015; 9:1843-57. https://doi.org/10.2147/DDDT.S78717

7. Taghizadeh DE, Ibrahim NM, Kadivar A, Kamalidehghan B, Farjam AS, Akbari Javar H. Preparation and characterization of a gastric floating dosage form of capecitabine. Biomed Res Int 2013; 1-8. https://doi.org/10.1155/2013/495319

8. Pawar HA, Gharat PR, Dhavale RV, Joshi PR, Rakshit PP. Development and evaluation of gastroretentive are floating tablet of an antihypertensive drug using hydrogenated cottonseed oil. ISRN Pharm 2013; 1-9. https://doi.org/10.1155/2013/137238

9. Meka VS, Nali SR, Songa AS, Kolapalli VR. Characterization and in vitro drug release studies of natural polysaccharide Terminalia Catappa Gum (Badam Gum). AAPS PharmSciTech 2012; 13:1451-64. https://doi.org/10.1208/s12249-012-98735 